\title{
Hydrolethalus syndrome
}

\author{
R Salonen, R Herva
}

Hydrolethalus syndrome is a lethal malformation syndrome with hydrocephalus, micrognathia, and polydactyly as the most obvious symptoms. Many of the patients are stillborn and the survival of the others has not been long. Hydrolethalus syndrome was recognised as a consequence of a study on Meckel syndrome in Finland. ${ }^{1}$ Apart from the first 28 cases, there are another 28 Finnish cases that we know about. This means an incidence of at least 1:20 000 in Finland. A few reports of the syndrome have been published from elsewhere. ${ }^{2-6}$

\section{Clinical findings (table)}

\section{PREGNANCY AND BIRTH}

Today, many cases are recognised during pregnancy by ultrasound, even in the case of the first affected of the family. ${ }^{7}$ Hydrocephalus with absent midline structures of the brain is seen. The size of the head may correspond to the gestational age, especially before 20 weeks, but there is usually obvious discrepancy with the size of the trunk of the fetus, which is small for dates. Later, the pregnancy is complicated by polyhydramnios and often preterm delivery. About $70 \%$ of the patients are stillborn. Those born alive survive a few minutes to a few hours at most.

CENTRAL NERVOUS SYSTEM MALFORMATIONS

All cases have a severe malformation of the central

Laboratory of Prenatal Genetics, Department of Obstetrics and Gynaecology, Helsinki University Central Hospital, SF-00290 Helsinki, Finland.

R Salonen

Department of Pathology, University of Oulu, Finland. R Herva

Correspondence to Dr Salonen.
Percentage frequency of the observed symptoms of 56 patients with hydrolethalus syndrome.

Polyhydramnios
Gestational age less than 38 weeks
Stillborn
Hydrocephalus
Occipital bone defect
Micrognathia
Cleft lip/palate
Anomalous nose
Small/deep set eyes
Anomalous/low set ears
Abnormal larynx/trachea
Defective lobulation of the lungs
Congenital heart disease
Urinary tract anomalies
Abnormal genitalia
Uterus duplex in females
Polydactyly
Fingers
Toes
Duplicated big toe
Club feet
Short limbs

nervous system. In most cases this is severe hydrocephalus. Three out of the 56 Finnish cases had anencephaly, that is, a major portion of the brain, skull, and scalp was absent (fig 1). One of these was a sib of a typical case with hydrocephalus. ${ }^{1}$ One case had hydranencephaly and the cerebral hemispheres were replaced by fluid. No case with alobar holoprosencephaly has been seen.

In the hydrocephalic cases, the hemispheres lie separated in the bottom of the skull. The upper midline structures, corpus callosum, and septum pellucidum are absent. The basal ganglia and the thalamus have developed. In some cases the pituitary or olfactory nerves are absent. The increased amount of cerebrospinal fluid is over the hemispheres covered by arachnoidea. The gyration of the brain is often grossly abnormal.

There is a cleft in the base of the skull in the midline of the occipital bone. This was a constant finding in the cases that were examined by ourselves and was found even in the anencephalic cases. Extending from the foramen magnum it forms a key- 
(a)

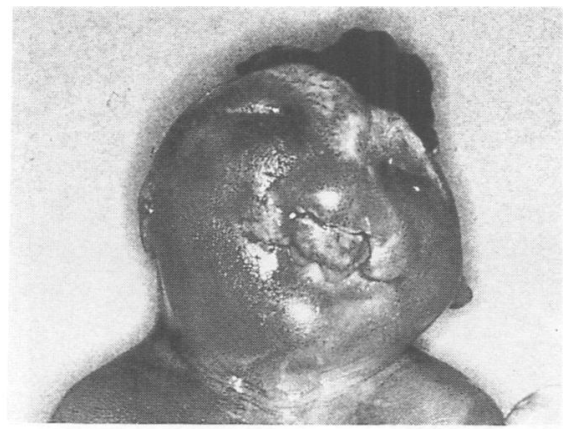

(b)

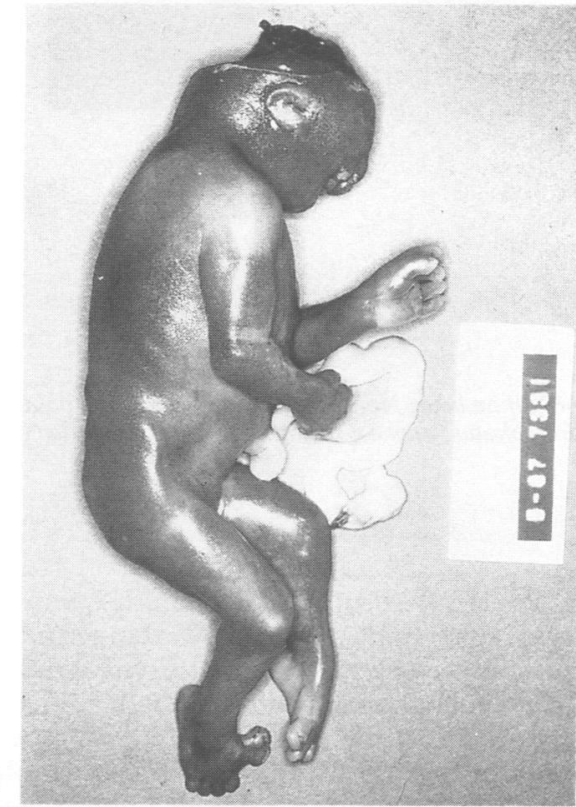

Figure 1 Hydrolethalus syndrome presenting with anencephaly, cleft lip (a), occipital bone defect, typical respiratory tract anomalies, truncus communis in the heart, and a duplicated big toe $(b)$.

hole shaped opening in the base of the skull. Sometimes the meninges or cerebellum are bulging through the defect in the neck beneath the intact skin.

\section{CRANIOFACIAL ABNORMALITIES}

The patients have micrognathia that is sometimes quite severe (fig 2). About half of the cases have cleft palate or lip (figs 1 and 3). The cleft lip is lateral or in the midline and clefts in the lower lip have also been seen. Some cases have a bifid nose. Often the nose is broad especially at the root. The eyes are wide set and sometimes also hypoplastic and deep set. The neck is often broad in proportion to the shoulders (figs 2 and 3).

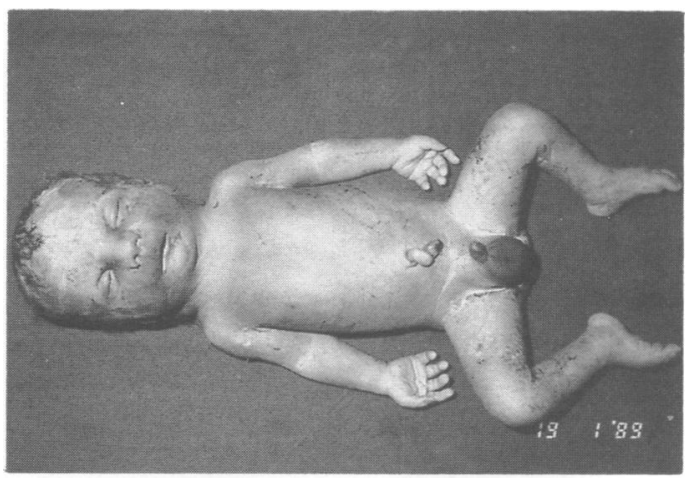

(a)

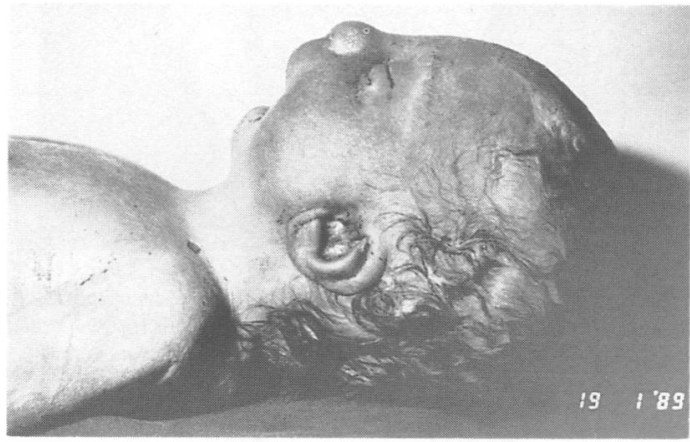

(b)

Figure 2 A stillborn boy at 36 weeks' gestation, weight $2050 \mathrm{~g}$. Note broad neck, broad (a) and high (b) nasal root, extreme micrognathia, and low set, abnormal ears. Necropsy showed hydrocephalus, occipital bone defect, tracheal stenosis, unilobular lungs, and common atrioventricular canal in the heart.

\section{THE RESPIRATORY ORGANS}

A malformed or hypoplastic larynx is a frequent finding. The trachea or the bronchi or both are stenotic or, rarely, dilated. The defective lobulation of the lungs leads in the most typical cases to bilateral unilobular lungs.

\section{CONGENITAL HEART DEFECTS}

Half of the patients have a congenital heart defect. Usually there is a large ventricular septal defect combined with an atrial septal defect that together form an atrioventricular canal. Other defects have also been found, for example, truncus communis.

\section{GENITOURINARY ANOMALIES}

Some cases have unilateral or bilateral hydronephrosis and in one case urethral atresia was also found. The structure of the kidneys is normal. Male patients sometimes have hypospadias. Half of the female 

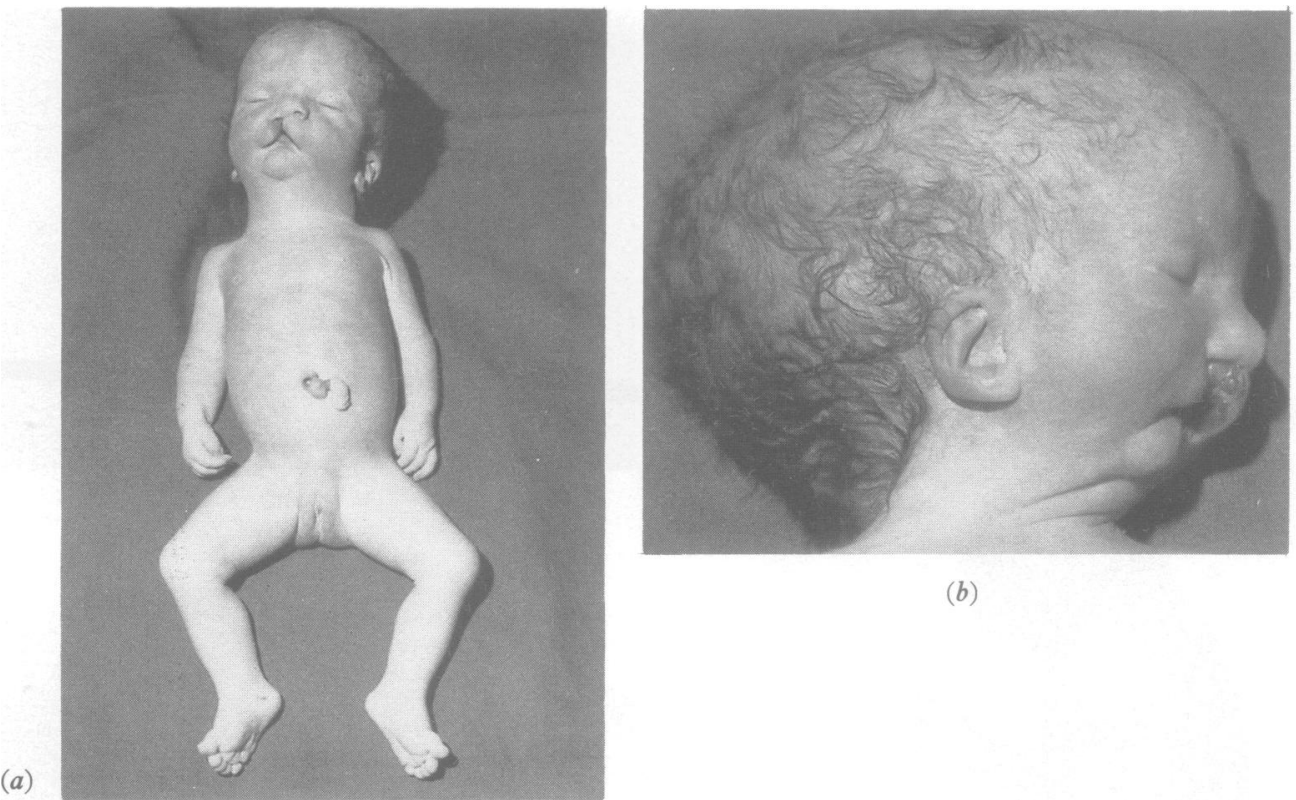

(b)

Figure 3 A female born at 37 weeks' gestation, weight $2675 \mathrm{~g}$. She lived for half an hour. Note broad neck, cleft lip and palate (a), micrognathia, and abnormal, low set ears $(b)$. Necropsy showed internal hydrocephalus, tracheal stenosis, defective lobulation of the lungs, one vagina, but a large double cyst instead of a uterus.

patients have a duplicated uterus, sometimes with associated malformations of the vagina. There has been no case of ambiguous genitalia.

\section{LIMB MALFORMATIONS}

About $80 \%$ of the patients have polydactyly. In the hands it is postaxial, but in the feet it is typically preaxial with a duplicated big toe (fig 4). Even if there is only one big toe, it is often bent medially (fig 4c). Club feet are also common. In some cases the extremities are short and the joints of the knees are abnormal. ${ }^{18}$

\section{OCCASIONAL ANOMALIES}

Unilateral agenesis of the diaphragm, omphalocele, agenesis of the tongue, and syndactyly have been seen in cases with hydrolethalus syndrome.

\section{Differential diagnosis}

Meckel syndrome with hydrocephalus differs from hydrolethalus syndrome principally in the cystic and fibrotic changes of the kidneys and liver. Trisomy 13 presents with similar anomalies. However, patients with trisomy 13 often have microcephaly, cystic kidneys, and only rarely polydactyly in the feet.
Krassikoff $e t a l^{4}$ also included Smith-Lemli-Opitż syndrome, septo-optic dysplasia, Warburg syndrome, oculoauriculovertebral dysplasia, Fryns syndrome, and asplenia/polysplenia syndromes in the differential diagnosis. Some of the reported cases, ${ }^{356}$ especially the milder ones with longer survival, probably represent another entity. In the 39 Finnish families with a typical case of hydrolethalus syndrome, there has never been extended survival.

\section{Inheritance}

The Finnish cases come from 39 families with 118 sibs; 30 males and 25 females were affected. In addition, there was one affected and aborted fetus whose sex was not recorded. The proportion of affected sibs was $0 \cdot 276$, corrected for truncate complete ascertainment by Apert's a priori method, and 0.215 corrected for truncate single ascertainment by omitting one affected sib from each sibship. ${ }^{9}$ The chromosomes of the patients studied have always been normal. This gives convincing evidence of autosomal recessive inheritance.

\section{Developmental basis}

Absent midline structures of the brain, most of the facial anomalies, the congenital heart defect, abnor- 

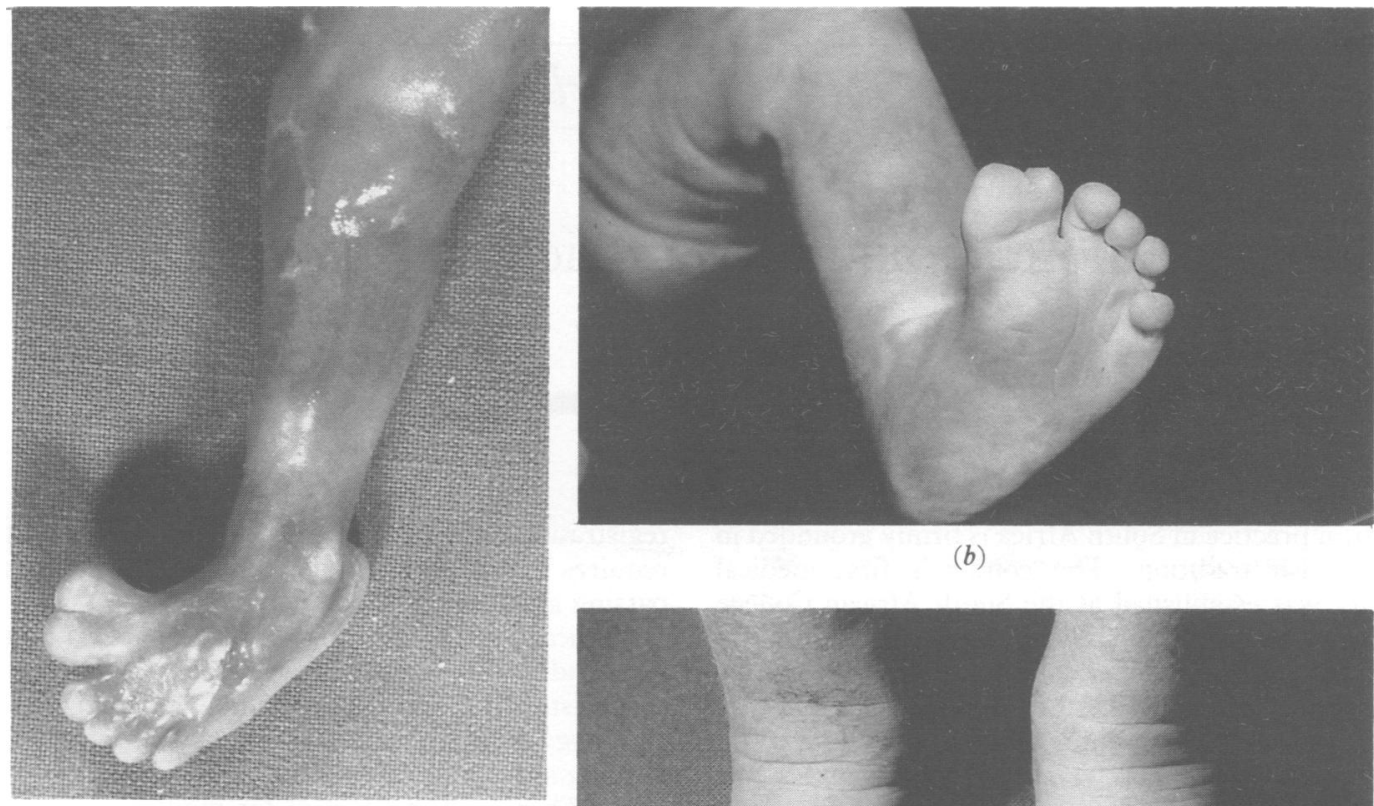

(b)

(a)

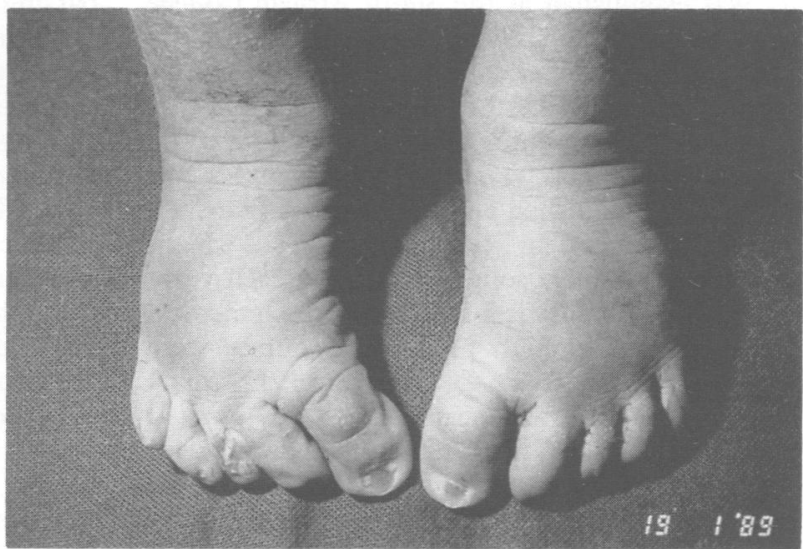

Figure 4 Typical duplicated big toes of hydrolethalus syndrome ( $a$ and $b$ ). The inward bent big toes of the case in fig 2 are a minimal form of this malformation (c).

malities of the respiratory tract, bifid uterus, and other genital anomalies can be regarded as defects of the midline developmental field. ${ }^{10}$

1 Salonen R, Herva R, Norio R. The hydrolethalus syndrome: delineation of a "new" lethal malformation syndrome based on 28 patients. Clin Genet 1981;19:321-30.

2 Adetoro AA, Komolafe F, Anjorin A. Hydrolethalus syndrome in consecutive African siblings. Pediatr Radiol 1984;14:422-4.

3 Toriello HV, Bauserman SC. Bilateral pulmonary agenesis: association with the hydrolethalus syndrome and review of the literature from a developmental field perspective. $\mathrm{Am} \mathrm{F}$ Med Genet 1985;21:93-103.
4 Krassikoff N, Konick L, Gilbert EF. The hydrolethalus syndrome. Birth Defects 1987;XXIII(1):411-9.

5 Anyane-Yeboa K, Collins M, Kupsky W, Maidman J, Malin J, Yeh M. Hydrolethalus (Salonen-Herva-Norio) syndrome: further clinicopathological delineation. Am 7 Med Genet 1987; 26:899-907.

6 Aughton DJ, Cassidy SB. Hydrolethalus syndrome: report of an apparent mild case, literature review, and differential diagnosis. Am 7 Med Genet 1987;27:935-42.

7 Hartikainen-Sorri AL, Kirkinen P, Herva R. Prenatal detection of hydrolethalus syndrome. Prenat Diagn 1983;3:219-24.

8 Herva R, Seppänen U. Roentgenologic findings of the hydrolethalus syndrome. Pediatr Radiol 1984;14:41-3.

9 Emery AEH. Methodology in medical genetics. An introduction to statistical methods. Edinburgh: Churchill Livingstone, 1976: 35-50.

10 Opitz JM, Gilbert EF. Editorial comment: CNS anomalies and the midline as a "developmental field". Am $\mathcal{f}$ Med Genet 1982;12:443-55. 